\title{
e-Migrinter
}

$5 \mid 2010$

Migrations dans les pays nordiques

\section{Les nouvelles migrations en Suède dans l'œuvre du romancier Henning Mankell}

\section{Marie Chabrol}

\section{(2) OpenEdition}

\section{Journals}

Édition électronique

URL : https://journals.openedition.org/e-migrinter/1912

DOI : 10.4000/e-migrinter. 1912

ISSN : 1961-9685

Éditeur

UMR 7301 - Migrinter

\section{Édition imprimée}

Date de publication : 28 avril 2010

Pagination : 81-84

ISSN : 1961-9685

\section{Référence électronique}

Marie Chabrol, «Les nouvelles migrations en Suède dans l'œuvre du romancier Henning Mankell », eMigrinter [En ligne], 5 | 2010, mis en ligne le 20 avril 2020, consulté le 20 mai 2021. URL : http:// journals.openedition.org/e-migrinter/1912 ; DOI : https://doi.org/10.4000/e-migrinter.1912 


\section{Les nouvelles migrations en Suède dans l'œuvre du romancier Henning Mankell}

$\mathbf{H}$ enning Mankell est aujourd'hui l'un des auteurs suédois les plus connus et traduits dans le monde. Né en 1948 à Stockholm, il commence à publier dans les années 1970, du théâtre et des romans, pour adultes et pour enfants. Très tôt attiré par les voyages, il découvre l'Afrique à vingt-quatre ans et décide d'y poser une partie de ses valises. D'abord en Guinée-Bissau, puis en Zambie et enfin au Mozambique, où il s'installe dans les années 1980. Il partage depuis sa vie entre l'Europe et l'Afrique, entre la Scanie enneigée et les planches du Théâtre Avenida de Maputo où, accompagné de sa femme Eva Bergman, il adapte et monte des pièces du répertoire européen avec une troupe de comédiens mozambicains.

Aux journalistes qui l'interviewent, Henning Mankell a pris l'habitude de se décrire lui-même "un pied dans la neige et un pied dans le sable ». Les voyages et le temps passé en Afrique lui permettent de poser un regard aiguisé sur l'évolution de la société suédoise : la montée des incertitudes et de l'individualisme dans les années 1990, la remise en question du modèle social scandinave, les bouleversements géopolitiques après la chute de l'URSS, mais aussi l'arrivée de nouvelles migrations en Suède et la recrudescence des actes xénophobes. C'est dans ce contexte que s'inscrit sa série de neuf romans policiers, débutée en 1991 et achevée en 1999, qui l'a fait connaître internationalement. Depuis, Henning Mankell continue d'explorer à travers le roman les multiples facettes de la société suédoise, tout en s'interrogeant sur les nouvelles migrations vers l'Europe et sur la responsabilité des Européens face aux drames de l'immigration.

\section{Marie Chabrol}

\section{Le roman policier comme miroir de la société suédoise}

Au début des années 1990, à chacun de ses retours du Mozambique, Henning Mankell constate la montée de l'individualisme et des sentiments xénophobes en Suède. À la manière des Grecs anciens, qui utilisaient le miroir du crime pour observer ce qui se passe au sein de la société, il décide d'utiliser le roman policier comme un miroir reflétant la montée de la violence dans la société suédoise.

Le décor des romans est situé à Ystad, une petite ville de 18000 habitants, en Scanie, région paisible et en apparence sans histoires. C'est pourtant là que se déroulent des meurtres toujours plus violents au fil des romans, actes de fous furieux, de tueurs en série, de vengeances ou liés à des trafics internationaux. $\mathrm{Au}$ fil des enquêtes, le personnage principal, l'inspecteur Kurt Wallander, voit ses repères basculer et ses représentations de la société suédoise s'effriter. Henning Mankell le décrit comme un policier tenace, souvent désarçonné devant des réalités dont il ne soupçonnait pas l'existence : les trafics entre pays baltes et pays scandinaves après la disparition de l'URSS, l'augmentation du nombre de demandeurs d'asile en Suède, les migrations clandestines, ainsi que le racisme et la xénophobie, dont la manifestation la plus visible transparait dans chaque roman à travers le désir de certains habitants d'Ystad de monter des milices d'auto-défense.

Meurtriers sans visage est le premier opus de la série et aborde frontalement la question des nouvelles migrations en Suède. Deux personnes âgées sont sauvagement 
assassinées dans leur ferme isolée et très rapidement le bruit court que ce sont des « étrangers» les coupables. "Étranger» devient alors un terme générique, désignant tout à la fois les pizzerias, les bazars tenus par ceux que l'on appelle les "nouveaux Suédois », que des travailleurs finlandais ou danois, mais surtout les réfugiés qui attendent dans des camps situés en pleine campagne que leur demande d'asile soit examinée. L'incendie criminel d'un camp et l'assassinat d'un réfugié somalien par des nationalistes membres de l'extrême-droite locale donnent l'occasion à l'inspecteur Kurt Wallander de prendre conscience du nombre croissant de migrants venus demander l'asile dans son pays, arrivés souvent clandestinement sur des ferries traversant la Baltique. À travers son regard, Henning Mankell fait aussi découvrir à ses lecteurs les visages inquiets et fatigués de ces hommes et de ces femmes, venus d'Iran, du Liban, de Somalie, d'Ethiopie, du Malawi, du Zaïre ou de Zambie, dont la couleur de peau les fait immédiatement repérer par le reste de la société suédoise - qui ferme les yeux sur les travailleurs clandestins venus d'Europe orientale. Après avoir résolu les meurtres, non sans avoir constaté le racisme latent au sein de la police suédoise, l'inspecteur écoute complètement effaré l'un de ses collègues conclure sur ces travailleurs venus des pays de l'Est: Si tu savais combien de gens vivent dans ce pays sans permis de séjour. Ily en a je ne sais pas combien. Ils logent les uns cher. les autres, ils falsifient leurs papiers, ils échangent leurs noms entre eux, travaillent au noir. Tu peux passer ta vie en Suède sans que personne se soucie de toi. Personne ne veut le croire. Mais c'est ainsi (Mankell, 2001 : 375). Qu'il décrive la suspicion et le manque d'accueil des habitants d'Ystad envers les réfugiés, ou l'exploitation des migrants venus d'Europe de l'Est, Henning Mankell dénonce à travers la question des nouvelles migrations le délitement du modèle suédois et le manque de solidarité de ses compatriotes.

Si les autres romans de la série des enquêtes de l'inspecteur Kurt Wallander ne traitent pas directement du thème de l'immigration autant que ce premier roman, il apparaît toutefois toujours en filigrane et souvent à contre-courant des clichés les plus répandus : le petit ami kenyan de la fille de Wallander, aux vêtements rasta, est un étudiant en médecine qui rentrera dans son pays ses études achevées, et les chauffeurs de taxis à l'accent arabe prononcé trouvent mieux leur chemin que les chauffeurs aux forts accents suédois. Enfin, de nombreux personnages secondaires, slaves, maghrébins et africains traversent les différentes intrigues et témoignent de l'intensification et de la diversification de l'immigration en Suède.

\section{L'engagement d'un auteur de roman et de théâtre}

Au fil des années, l'intérêt d'Henning Mankell pour la question des migrations internationales ne faiblit pas. Mais il déplace son regard, passant de la description des «nouveaux Suédois» à une interrogation plus globale sur les difficultés dans les pays de départ, qui poussent de plus en plus d'hommes et de femmes à prendre la route ; sur la fermeture des frontières de l'espace Schengen, qui rend ces routes de plus en plus difficiles et, enfin, sur la responsabilité des Européens face aux drames de l'immigration clandestine. En 2009, dans une interview à un journaliste de la revue XXI, comme à tous ceux qui l'interrogent sur ce sujet, Henning Mankell déclare : pour moi, il y a un centre symbolique en Europe. C'est la petite île de Lampedusa, au sud de l'Italie, où viennent s'échouer chaque année les cadavres des immigrés clandestins venus d'Afrique. Profitant de sa notoriété pour faire entendre sa voix sur le sujet, Mankell consacre plusieurs œuvres, romanesques ou théâtrales, au thème des migrations clandestines, dont le roman TeaBag, paru en France en 2007.

Tea-Bag est le nom que se donne une jeune migrante africaine qui, après avoir passé plusieurs mois dans un camp de rétention en Espagne, parvient par ses 
propres moyens à rejoindre la Suède. Le premier chapitre, certainement le plus magistral du roman, laisse entrevoir au lecteur la détresse psychologique des réfugiés parqués dans ce camp, eux qui ont tout laissé dans leur pays de départ, perdu une partie de leurs compagnons de voyage dans des conditions dramatiques et qui sont désormais bloqués aux portes de l'Europe. L'Europe nous a abandonné avant même que nous touchions terre songe Tea-Bag chaque matin en s'éveillant sous sa toile de tente, avant d'entamer une journée identique à celle de la veille, où son seul combat, comme celui de ses codétenus, est de ne pas se faire identifier pour ne pas être reconduite dans son pays d'origine.

En Suède, où elle vit dans la clandestinité, Tea-Bag croise le chemin d'un poète suédois égocentrique et égocentré, amené contre son gré à animer des ateliers d'écriture pour jeunes migrants dans un quartier populaire de la banlieue de Göteborg. Peu à peu, l'écriture permet de nouer des liens d'amitié et de raconter des histoires migratoires douloureuses : celle de Tea-Bag, dont le père a été assassiné, le frère réduit en esclavage, et qui a traversé l'Afrique, la Méditerranée et l'Europe pour atteindre finalement une certaine paix en Suède ; celle de Leilla, une lycéenne d'origine iranienne, oppressée par sa famille venue chercher l'asile en Suède lorsqu'elle était enfant ; et enfin celle de Tania, la fille de l'Est sans papiers, qui a fui la prostitution forcée et traversé la Baltique à la rame.

Parabole sans artifices du rôle de l'écrivain, Tea-Bag est un roman où le poète ouvre peu à peu les yeux, découvrant une face de la Suède dont il ignore tout : les destins douloureux des trois jeunes femmes et leur courage sans faille, les aspirations des enfants issus de l'immigration, les sanspapiers cachés dans les sous-sols des églises et, petit clin d'œil malicieux dans un roman par ailleurs sans aucune trace d'humour ou de légèreté, ces chauffeurs de taxis, qui parlent un suédois mal assuré avec un fort accent de
Göteborg, mais conduisent toujours à bon port leurs passagers.

Salué par la critique internationale et par le public, Tea-Bag est un roman engagé, traduit dans de nombreuses langues. Henning Mankell a depuis écrit d'autres histoires, sur la Suède et sur le Mozambique et monté d'autres pièces au Théâtre Avenida de Maputo, mais il a toujours à cœur de parler des drames de l'immigration et de la responsabilité de l'Europe dans ses entretiens avec des journalistes.

Marie Chabrol

Doctorante

MIGRINTER - UMR 6588

CNRS / Université de Poitiers

ATER

Université Paris 1 Panthéon-Sorbonne machabrol@gmail.com

\section{Bibliographie}

La date indiquée correspond à la première édition française en livre de poche, dans la collection Points du Seuil. La date entre crochet correspond à la première publication des romans en Suède. Le premier éditeur français d'Henning Mankell a été Christian Bourgeois.

\section{Les romans évoqués dans cette note}

Mankell, Henning (2001) [1991] Meurtriers sans visages, Paris, Seuil, 386 p. (coll. Points Policier).

Mankell, Henning (2003) [1992] Les chiens de Riga, Paris, Seuil, 322 p. (coll. Points Policier).

Mankell, Henning (2004) [1993] La lionne blanche, Paris, Seuil, 488 p. (coll. Points Policier). 
Mankell, Henning (2004) [1994] L'bomme qui souriait, Paris, Seuil, 421 p. (coll. Points Policier).

Mankell, Henning (1999) [1995] Le guerrier solitaire, Paris, Seuil, 553 p. (coll. Points Policier).

Mankell, Henning (2000) [1996] La cinquième femme, Paris, Seuil, 581 p. (coll. Points Policier)

Mankell, Henning (2001) [1997] Les morts de la Saint-Jean, Paris, Seuil, 563 p. (coll. Points Policier).

Mankell, Henning (2002) [1998] La muraille invisible, Paris, Seuil, 518 p. (coll. Points Policier).
Mankell, Henning (2005) [1999] Avant le gel, Paris, Seuil, 487 p. (coll. Points Policier).

Mankell, Henning (2007) [2001] Tea-Bag, Paris, Seuil, 343 p. (coll. Points)

\section{À lire sur Henning Mankell :}

Raynal, Patrick (2009) Le commissaire se cache au Mozambique, XXI, Hors-série, pp. 30-41. 